Original Article

\title{
The effect of olfactory stimuli on the balance ability of stroke patients
}

\author{
Mi-Na Gim, PT ${ }^{1)}$, Sang-Bin Lee, PT, PhD ${ }^{1)}$, Kyung-Tae Yoo, PT, PhD ${ }^{1)}$, Ji-Young Bae, PT ${ }^{1)}$, \\ Mi-Kyoung KIm, PT ${ }^{1)}$, Jung-Hyun Choi, PT, $\mathrm{PhD}^{1)^{*}}$ \\ 1) Department of Physical Therapy, Namseoul University: 21 Maeju-ri, Sungwan-eup, Seobuk-gu, \\ Chonan-si 331-707, Republic of Korea
}

\begin{abstract}
Purpose] The present study attempted to identify the effect of olfactory stimulation on the balance ability of stroke patients. [Subjects] Thirty-three (33 males) stroke patients participated in the study. The stroke patients were divided into three groups: a black pepper oil (BPO) group ( $\mathrm{n}=11)$, lavender oil (LVO) group ( $\mathrm{n}=11)$, and distilled water (DW) group ( $\mathrm{n}=11$ ). [Methods] Two sessions (control trial/stimulus trial) of Romberg's test (eyes open $1 \mathrm{~min} /$ eyes closed $1 \mathrm{~min}$ ) were conducted on a force platform to measure the data for the COP (center of pressure). Olfactory stimulation was provided at as a stimulus. [Results] With the eyes open, a statistically significant difference was found in average anterior posterior displacement (Ymean) and average medial lateral displacement (Xmean) among the three groups when comparing the groups before and after stimulation. The comparison between the eyes open and eyes closed conditions in each group showed a significant difference in the area of the $95 \%$ confidence ellipse (area) and Xmean of the BPO group and in the area of the LVO group (area, Xmean). [Conclusion] The findings indicate that the interaction of brain areas activated by the olfactory stimulation exerts an influence on the balance ability of stroke patients.

Key words: Stroke, Olfactory stimulation, Balance
\end{abstract}

(This article was submitted May 21, 2014, and was accepted Jul. 24, 2014)

\section{INTRODUCTION}

A stroke is an acute onset of neurological dysfunction resulting from an abnormality of cerebral circulation ${ }^{1)}$ and is one of the major causes of long-term disability ${ }^{2}$. Stroke patients' sensory, motor, cognitive, and emotional disabilities impose restrictions on their basic activities of daily living ${ }^{3)}$ Disabilities in the form of reduced postural balance, postural control, and functional movement are general problems of stroke patients ${ }^{4}$. Impairment of balance control is a main problem in these patients, since it may greatly affect their mobility and independence and often increases the risk of falls ${ }^{5,6)}$

Balance deficits can be identified from observing increased postural sway in stroke patients during quiet standing ${ }^{7,8)}$. Many studies on quiet standing in stroke patients have utilized force platform technology to evaluate weight bearing and body sway; based on the location and movement of the COP of the ground reaction force ${ }^{9}$. Analysis of the movement of the COP obtained from data collected using a force platform is a general method to measure postural sway with quiet standing ${ }^{10)}$.

*Corresponding author. Jung-Hyun Choi (E-mail: rightmind@nsu.ac.kr)

(C2015 The Society of Physical Therapy Science. Published by IPEC Inc. This is an open-access article distributed under the terms of the Creative Commons Attribution Non-Commercial No Derivatives (by-ncnd) License $<$ http://creativecommons.org/licenses/by-nc-nd/3.0/> .
Most of the research on quiet standing makes use of a kinetic measurement method in which the anterior-posterior and medial-lateral displacements of the COP are calculated on a force platform ${ }^{11)}$. In general, evaluation of balance ability of stroke patients depends on the following four indices: mean COP velocity (velocity), area of the $95 \%$ confidence ellipse (area), average anterior-posterior displacement (Ymean), and average medial-lateral displacement $(\text { Xmean })^{12-15)}$.

An individual's postural control is a complex motor task that is controlled by hierarchical neural systems including the spinal cord, brainstem, cerebellum, basal ganglia, and the cerebral cortex ${ }^{16)}$. Standing balance control, in turn, is a complex sensorimotor action based on automated and reflexive spinal programs under the influence of the brainstem, cerebellum, cortex, and several distinct and separate supraspinal centers ${ }^{17)}$. In order to maintain postural control a series of processes are required that involve various systems, including sensory information for visual sense, vestibular sense, proprioception, cognitive integration, cerebellum function, and the sensory-motor feedback system $^{18,19)}$.

It has been reported that odor provides a strong stimulation to a wide area of the cerebral cortex ${ }^{20)}$ and that olfactory stimulation activates various regions of the brain as well as the orbitofrontal corte ${ }^{21)}$. Other research has suggested that the cerebellum is involved in odor information processing $^{22,23)}$. It has also been found that patients with localized cerebellar atrophies and focal cerebellar lesions showed olfactory impairment ${ }^{24)}$. All these findings may lead us to as- 
sume that olfactory stimulation is closely related to various regions of the brain.

Some recent research has suggested that olfactory stimulation may increase the postural stability of the elderly ${ }^{25)}$. It has also been reported that olfactory stimulation increased the gait ability of the elderly ${ }^{26}$ ) and that it decreased their risk of falls ${ }^{27)}$. Many studies have been carried out to identify the relationship between olfactory stimulation and postural control, but not much has been reported on stroke patients. This study attempted to identify the effect of olfactory stimulation on the balance ability of stroke patients having balance problems.

\section{SUBJECTS AND METHODS}

Table 1 shows the general physical characteristics of the group of chronic stroke patients used as subjects, who met the following criteria: they were chronic stroke patients who had hemiplegia from strokes for at least 6 months; had normal olfactory function diagnosed with an olfactory identification test; scored greater than 24 points on the mini-mental state examination (MMSE) test and showed no problem in communication, could walk $10 \mathrm{~m}$ by themselves did not have any disease in musculoskeletal, cardiovascular, or endocrine system, who did not take any medicine that a could influence posture and balance passed the third stage of the Brunnstrom recovery scale; and agreed to voluntarily participate in the present research. Written informed consent has been obtained from each subject or patient. The Ethics Committee of Namseoul University, South Korea, also approved the study. The IRB approval number is Research-140421-3.

The 33 subjects were randomly assigned to one of three subgroups: the black pepper, lavender, and distilled water. Black pepper, lavender oil (Absoulte aromas Ltd. Alton, England), and distilled water were used as olfactory stimuli for the subjects. The experiment was conducted for all three groups between 10 to 11 in the morning. Measurement of COP values with quiet standing was carried out with a BT4 force platform (Hur Laps Oy, Tampere, Finland). The participants did performed two sessions (control trial/stimulus trial) of Romberg's test (eyes open 1 min/eyes closed $1 \mathrm{~min}$ ) on the force platform (BT4, Hur Laps Oy, Tampere, Finland).

First, a Romberg's test (for COP measurement) was conducted before olfactory stimuli for one minute with the eyes open, and this was followed by two minutes of rest and then performance of the test again for one minute with the eyes closed. After a four minute of rest, the olfactory stimulus was given, and the COP was measured for one minute with the eyes open; this was followed by two minutes of rest and then measurement of the COP again for one minute with the eyes closed. The olfactory stimulus was given to the patients via an aroma necklace that they did not wear during rest periods. The subjects sat in a chair comfortably while resting ${ }^{25)}$.

COP excursion was tested using a four-channel portable force platform (Hur Labs BT4) that was calibrated prior to testing; the channels were checked before every test. The
Table 1. Subject characteristics

\begin{tabular}{lccc}
\hline & $\begin{array}{l}\text { BPO } \\
\text { mean } \pm \text { SD }\end{array}$ & $\begin{array}{l}\text { LVO } \\
\text { mean } \pm \text { SD }\end{array}$ & $\begin{array}{l}\text { DW } \\
\text { mean } \pm \text { SD }\end{array}$ \\
\hline Gender (male/female) & $11 / 0$ & $11 / 0$ & $11 / 0$ \\
Age (years) & $58.7 \pm 15.1$ & $62.6 \pm 10.7$ & $57.5 \pm 10.1$ \\
Height (cm) & $170.4 \pm 4.4$ & $169.8 \pm 5.3$ & $167.3 \pm 7.2$ \\
Weight (kg) & $67.4 \pm 8.0$ & $63.9 \pm 6.8$ & $64.7 \pm 6.8$ \\
Stroke type (number) & & & \\
Ischemic/hemorrhagic & $6 / 5$ & $5 / 6$ & $7 / 4$ \\
Affected side (number) & & & \\
Left/Right & $8 / 3$ & $10 / 1$ & $8 / 3$ \\
Time since stroke (month) & $25.4 \pm 12.4$ & $22.4 \pm 16.1$ & $30.4 \pm 16.5$ \\
MMSE (score) & $28.2 \pm 2.2$ & $27.55 \pm 2.7$ & $25.73 \pm 2.2$ \\
Brunnstrom (stage) & $4.36 \pm 0.8$ & $4.00 \pm 0.8$ & $4.18 \pm 0.8$ \\
\hline
\end{tabular}

BPO, black pepper oil; LVO, lavender oil; DW, distilled water; MMSE, mini-mental

Patients were instructed to look straight ahead and stand as still as possible with their arms hanging down. The foot position was standardized: patients stood with a $2 \mathrm{~cm}$ heel-toheel distance and an angle of $30^{\circ}$ between the feet. The test was carried out with the eyes opens, focusing on a point $2 \mathrm{~m}$ ahead, and with the eyes closed. The participants stood still for at least $5 \mathrm{~s}$ (pre-phase) before measurement. After the pre-phase, the COP was measured for the next 60 seconds. Signals were sampled at $200 \mathrm{~Hz}$ and filtered with a digital low-pass filter at a $7.8 \mathrm{~Hz}$ cutoff frequency prior to sampling; signals were filtered with two low-pass filters, with the first-stage filter being a is sinc 3 type and the secondstage filter being a 22-tap filter.

In the current research, the area of the $95 \%$ confidence ellipse (area), average anterior-posterior displacement (Ymean), and average medial-lateral displacement (Xmean) were selected as the COP values.

SPSS Statistics 18.0 program for Windows was used in this research to carry out all statistical analyses. The general characteristics of the subjects were analyzed with the Kolmogorov-Smirnov test. Multivariate analysis of variance was to analyze variable effects based on the three balance ability factors, area, Xmean, and Ymean, of the three groups. A paired t-test was also conducted to compare presence and absence of sight: the eyes open and eyes closed conditions. The level of significance was set at 0.05 .

\section{RESULTS}

The three groups showed changes in area, Xmean, and Ymean before and after olfactory stimuli with the eyes open and eyes closed, as shown in Table 2. With the eyes open, a statistically significant difference was not found $(p<0.05)$ among the three groups in area, but significant differences were found in Xmean and Ymean in comparisons of the values before and after olfactory stimulus. With the eyes closed, on the other hand, no significant difference was found in area, Xmean, and Ymean among the three groups $(\mathrm{p}>0.05)$.

There were also changes in area, Xmean, and Ymean 
Table 2. Differences among the three groups in area, Xmean and Ymean before and after olfactory stimuli with eyes open and closed

\begin{tabular}{cclcc}
\hline Condition & Variable & Group & $\begin{array}{c}\text { Pre } \\
\text { mean } \pm \text { SD }\end{array}$ & $\begin{array}{c}\text { Post } \\
\text { mean } \pm \text { SD }\end{array}$ \\
\hline & & BPO & $521.3 \pm 397.6$ & $394.6 \pm 249.1$ \\
& Area & LVO & $602.5 \pm 594.1$ & $500.2 \pm 401.2$ \\
& $\left(\mathrm{~mm}^{2}\right)$ & DW & $570.0 \pm 346.5$ & $458.8 \pm 290.1$ \\
& & BPO* & $22.8 \pm 16.3$ & $16.2 \pm 11.9$ \\
EO & Xmean & LVO* & $21.0 \pm 14.8$ & $14.3 \pm 11.5$ \\
& $(\mathrm{~mm})$ & DW & $20.8 \pm 20.8$ & $16.9 \pm 11.7$ \\
& & BPO* & $-15.7 \pm 12.8$ & $-25.5 \pm 12.7$ \\
& Ymean & LVO & $-17.7 \pm 15.9$ & $-21.1 \pm 15.9$ \\
& $(\mathrm{~mm})$ & DW & $-14.4 \pm 14.7$ & $-17.3 \pm 17.8$ \\
& & BPO & $528.1 \pm 497.4$ & $563.3 \pm 364.7$ \\
& Area & LVO & $580.4 \pm 510.3$ & $602.7 \pm 487.1$ \\
& $\left(\mathrm{~mm}{ }^{2}\right)$ & DW & $758.1 \pm 635.9$ & $632.8 \pm 489.4$ \\
& & BPO & $21.5 \pm 13.9$ & $18.2 \pm 11.8$ \\
EC & Xmean & LVO & $22.6 \pm 13.9$ & $15.0 \pm 12.5$ \\
& $(\mathrm{~mm})$ & DW & $21.3 \pm 21.8$ & $17.8 \pm 15.0$ \\
& & BPO & $-14.0 \pm 12.6$ & $-23.9 \pm 13.3$ \\
& Ymean & LVO & $-18.3 \pm 14.8$ & $-19.1 \pm 15.9$ \\
& $(\mathrm{~mm})$ & DW & $-9.3 \pm 25.7$ & $-15.0 \pm 19.7$ \\
\hline
\end{tabular}

*Expressed as $\mathrm{p}<0.05$. BPO, black pepper oil; LVO, lavender oil; DW, distilled water; area, area of the $95 \%$ confidence ellipse; Ymean, average anterior-posterior displacement; Xmean, average medial-lateral displacement; EO, eyes open; EC, eyes closed

within each group with the eyes open and eyes closed (Table $3)$. In the comparison of the eyes open and eyes open conditions for each group, it was found that the area and Xmean of the BPO group and the area of the LVO group showed significant differences $(p<0.05)$. However, no significant difference was found in comparison of the eyes open and eyes closed conditions in terms of the comparison in Ymean of the BPO group, Xmean and Ymean of the LVO group and all three indices in the DW group.

\section{DISCUSSION}

The present research attempted to identify the impact of olfactory stimuli on the balance ability of stroke patients. It was found that olfactory stimuli decreased the Xmean (BPO, LVO) and Ymean (BPO) values with the eyes open.

Similar results were reported in previous research. Freeman S et al. ${ }^{25)}$, for instance, found in their test of balance ability with black pepper oil and lavender oil as olfactory stimuli that the COP values (RMS velocity and trajectory length in the medial-lateral and anterior-posterior directions) decreased significantly. Ebihara et al. ${ }^{26)}$ also reported that the TUG (Timed Up and Go) test score of the elderly significantly decreased after being given olfactory stimuli of lavender oil and grapefruit oil. Sakamoto et al. ${ }^{27)}$ also found an interesting result: seniors showed significantly lowered risk of falls after being given olfactory stimuli consisting of a lavender scent for 12 months. Thus, it can be
Table 3. Eyes open vs. eyes closed: differences in area, Xmean, and Ymean of each group before and after olfactory stimulation

\begin{tabular}{llcc}
\hline Group & Variable & $\begin{array}{c}\text { EO } \\
\text { mean } \pm \text { SD }\end{array}$ & $\begin{array}{c}\text { EC } \\
\text { mean } \pm \text { SD }\end{array}$ \\
\hline \multirow{3}{*}{ BPO } & Area* $\left(\mathrm{mm}^{2}\right)$ & $126.7 \pm 213.9$ & $-35.2 \pm 290.1$ \\
& Xmean* $(\mathrm{mm})$ & $6.6 \pm 12.2$ & $3.2 \pm 10.9$ \\
& Ymean $(\mathrm{mm})$ & $9.8 \pm 11.0$ & $9.9 \pm 8.3$ \\
& Area* $\left(\mathrm{mm}^{2}\right)$ & $602.5 \pm 594.1$ & $-102.5 \pm 170.0$ \\
LVO & Xmean $(\mathrm{mm})$ & $-1.6 \pm 13.3$ & $-0.6 \pm 5.4$ \\
& Ymean & $0.6 \pm 6.1$ & $-1.9 \pm 8.1$ \\
& Area $\left(\mathrm{mm}^{2}\right)$ & $-188.1 \pm 463.8$ & $-173.9 \pm 270.2$ \\
DW & Xmean $(\mathrm{mm})$ & $-0.5 \pm 18.4$ & $-0.9 \pm 6.6$ \\
& Ymean $(\mathrm{mm})$ & $-5.0 \pm 15.1$ & $-2.2 \pm 8.0$ \\
\hline
\end{tabular}

*Expressed as $\mathrm{p}<0.05$. BPO, black pepper oil; LVO, lavender oil; DW, distilled water; area, area of the $95 \%$ confidence ellipse; Ymean, average anterior-posterior displacement; Xmean, average medial-lateral displacement; EO, eyes open; EC, eyes closed

concluded that olfactory stimuli enhance balance ability, which supports previous research.

Miyanari et al. ${ }^{21)}$ have reported that many areas of the brain can be activated by olfactory stimuli: the subthalamic nucleus in the left hemisphere and precentral gyrus, insula right hemisphere, and right superior frontal gyrus, as well as the orbitofrontal cortex. Also, cerebellar activity was consistently observed in functional imaging studies of olfaction $^{22,23)}$. Thus, it was found that olfactory stimuli can activate other areas of the brain as well as olfactory function.

Previous research has found that performance of balance tasks may activate many regions of the brain: the parietal lobe, prefrontal cortex, sensorimotor regions, precuneus, cingulate cortex, thalamus, frontal gyri, temporal gyri, cerebellum, vermis, basal ganglia, supplementary motor area, insula, supramarginal gyrus, precentral gyrus, corpus callosum, and caudate nucleus ${ }^{28-30)}$. Thus, it might be possible to conclude in general that performing balance tasks would lead to activation of various regions of the brain.

Of the abovementioned activated regions, the insula is considered one of the most activated regions in functional neuroimaging research ${ }^{31,32)}$. It is known that it is involved in the input of visceral motor/sensory, gustatory, olfactory, vestibular/auditory, visual, verbal, pain, and sensory/motor information; auditory processing with respect to music; eating; and processing of attention and emotion ${ }^{33-36)}$. Craig $^{37)}$ argued that the insula integrates and processes various types of stimuli.

$\mathrm{Ng}^{38}$ ) suggested that maintenance of balance must involve simultaneous and continuous data processing of multiple systems including sensory information; visual, vestibular, and proprioceptive senses; cognitive integration; attention and executive function; cerebellar function; and sensory and motor feedback. The insula contains the vestibular system ${ }^{39)}$. It has been reported that vestibular stimulation leads to activation of the brain ${ }^{40)}$, specifically, the right posterior insula ${ }^{41)}$. Also, many functional neuroimaging 
studies of olfaction have continuously observed cerebellar $\operatorname{activities}^{22,23)}$.

Together, the abovementioned studies suggest that olfactory stimuli can activate the insula and cerebellum and that performing balance tasks can activate the insula, cerebellum, and vestibular system. Thus, the combination and interaction of olfactory stimuli and performing balance tasks can activate various regions of the brain, and help enhance the balance ability of stroke patients. The COP values showed significant differences when black pepper and lavender scents were used as olfactory stimuli, but no difference was found with distilled water. The COP values increased with the eyes closed. Such a result can be explained by a previous study, which found that balance control needs visual, vestibular, and proprioceptive senses ${ }^{35}$, and another study, which found that postural control was dependent on visual information in stroke patients when standing ${ }^{42}$. Different COP values depending on the presence/absence of sight might be a natural result, since blockage of sight results in increased body sway, as sight is one of the important elements for postural control. Visual dependence of stroke patients also contributed to the difference in COP values in the present study. The finding of significant differences in COP values in the black pepper and lavender scent groups might lead us to conclude that olfactory stimuli affect balance ability.

Freeman $\mathrm{S}$ et al. ${ }^{25}$ ) found that the COP values of the elderly decreased with the eyes closed, but it was found in this research that the COP values of stroke patients decreased with the eyes open. This finding explains why we could not greatly lower the COP values of stroke patients by providing olfactory stimulus with the eyes closed, since they show visual dependence behavior ${ }^{42)}$.

It was found that an olfactory stimulus led to improvement of balance ability in the stroke patients. This result might be attributable to strong activation and interaction of various areas of the brain as result of the olfactory stimulus and their performance of balance tasks. Further research should be carried before making any generalizations, since not much research has been carried out on the relationship between an olfactory stimulus and balance.

\section{REFERENCES}

1) O'Sullivan SB, Schmitz TJ: Stroke. In: Physical Rehabilitation Assessment and Treatment, 5th ed. Philadelphia: FA Davis, 2007, pp 705-776.

2) Roger VL, Go AS, Lloyd-Jones DM, et al.: Heart disease and stroke statistics - 2012 update: a report from the American Heart Association. Circulation, 2012, 12: 2-220. [Medline]

3) Hochstenbach J, Donders R, Mulder T, et al.: Long-term outcome after stroke: a disability-orientated approach. Int J Rehabil Res, 1996, 19: 189200. [Medline] [CrossRef]

4) Williams BK, Galea MP, Winter AT: What is the functional outcome for the upper limb after stroke? Aust J Physiother, 2001, 47: 19-27. [Medline] [CrossRef]

5) Fong KN, Chan CC, Au DK: Relationship of motor and cognitive abilities to functional performance in stroke rehabilitation. Brain Inj, 2001, 15: 443-453. [Medline] [CrossRef]

6) Mackintosh SF, Hill KD, Dodd KJ, et al.: Balance score and a history of falls in hospital predict recurrent falls in the 6 months following stroke rehabilitation. Arch Phys Med Rehabil, 2006, 87: 1583-1589. [Medline] [CrossRef]

7) Corriveau H, Hébert R, Raîche M, et al.: Evaluation of postural stability in the elderly with stroke. Arch Phys Med Rehabil, 2004, 85: 1095-1101.
[Medline] [CrossRef]

8) Ha H, Cho K, Lee W: Reliability of the good balance system(®) for postural sway measurement in poststroke patients. J Phys Ther Sci, 2014, 26 : 121-124. [Medline] [CrossRef]

9) Winter DA, Prince F, Frank JS, et al.: Unified theory regarding A/P and $\mathrm{M} / \mathrm{L}$ balance in quiet stance. J Neurophysiol, 1996, 75: 2334-2343. [Medline]

10) Winter DA, Patla AE, Prince F, et al.: Stiffness control of balance in quiet standing. J Neurophysiol, 1998, 80: 1211-1221. [Medline]

11) El-Kahky AM, Kingma H, Dolmans M, et al.: Balance control near the limit of stability in various sensory conditions in healthy subjects and patients suffering from vertigo or balance disorders: impact of sensory input on balance control. Acta Otolaryngol, 2000, 120: 508-516. [Medline] [CrossRef]

12) Cho K, Lee W: Changes in postural sway according to footwear types of hemiparetic stroke patients. J Phys Ther Sci, 2014, 26: 861-864. [Medline] [CrossRef]

13) Lee J, Seo K: The effects of stair walking training on the balance ability of chronic stroke patients. J Phys Ther Sci, 2014, 26: 517-520. [Medline] [CrossRef]

14) Jung J, Lee J, Chung E, et al.: The effect of obstacle training in water on static balance of chronic stroke patients. J Phys Ther Sci, 2014, 26: $437-$ 440. [Medline] [CrossRef]

15) Han SK, Kim MC, An CS: Comparison of effects of a proprioceptive exercise program in water and on land the balance of chronic stroke patients. J Phys Ther Sci, 2013, 25: 1219-1222. [Medline] [CrossRef]

16) Fujimoto H, Mihara M, Hattori N, et al.: Cortical changes underlying balance recovery in patients with hemiplegic stroke. Neuroimage, 2014, 85 : 547-554. [Medline] [CrossRef]

17) Drew T, Prentice S, Schepens B: Cortical and brainstem control of locomotion. Prog Brain Res, 2004, 143: 251-261. [Medline] [CrossRef]

18) Woollacott M, Shumway-Cook A: Attention and the control of posture and gait: a review of an emerging area of research. Gait Posture, 2002, 16: 1-14. [Medline] [CrossRef]

19) Iqbal ZA, Rajan R, Khan SA, et al.: Effect of deep cervical flexor muscles training using pressure biofeedback on pain and disability of school teachers with neck pain. J Phys Ther Sci, 2013, 25: 657-661. [Medline] [CrossRef]

20) de Araujo IE, Rolls ET, Velazco MI, et al.: Cognitive modulation of olfactory processing. Neuron, 2005, 46: 671-679. [Medline] [CrossRef]

21) Miyanari A, Kaneoke Y, Noguchi Y, et al.: Human brain activation in response to olfactory stimulation by intravenous administration of odorants. Neurosci Lett, 2007, 423: 6-11. [Medline] [CrossRef]

22) Qureshy A, Kawashima R, Imran MB, et al.: Functional mapping of human brain in olfactory processing: a PET study. J Neurophysiol, 2000, 84: 1656-1666. [Medline]

23) Ferdon S, Murphy C: The cerebellum and olfaction in the aging brain a functional magnetic resonance imaging study. Neuroimage, 2003, 20: 12-21. [Medline] [CrossRef]

24) Mainland JD, Johnson BN, Khan R, et al.: Olfactory impairments in patients with unilateral cerebellar lesions are selective to inputs from the contralesional nostril. J Neurosci, 2005, 25: 6362-6371. [Medline] [CrossRef]

25) Freeman $S$, Ebihara $S$, Ebihara T, et al.: Olfactory stimuli and enhanced postural stability in older adults. Gait Posture, 2009, 29: 658-660. [Medline] [CrossRef]

26) Ebihara S, Nikkuni E, Ebihara T, et al.: Effects of olfactory stimulation on gait performance in frail older adults. Geriatr Gerontol Int, 2012, 12: 567-568. [Medline] [CrossRef]

27) Sakamoto Y, Ebihara S, Ebihara T, et al.: Fall prevention using olfactory stimulation with lavender odor in elderly nursing home residents: a randomized controlled trial. J Am Geriatr Soc, 2012, 60: 1005-1011. [Medline] [CrossRef]

28) Malouin F, Richards CL, Jackson PL, et al.: Brain activations during moto imagery of locomotor-related tasks: a PET study. Hum Brain Mapp, 2003, 19: 47-62. [Medline] [CrossRef]

29) Zwergal A, Linn J, Xiong G, et al.: Aging of human supraspinal locomotor and postural control in fMRI. Neurobiol Aging, 2012, 33: 1073-1084. [Medline] [CrossRef]

30) Karim HT, Sparto PJ, Aizenstein HJ, et al.: Functional MR imaging of a simulated balance task. Brain Res, 2014, 1555: 20-27. [Medline] [CrossRef]

31) Nelson SM, Dosenbach NU, Cohen AL, et al.: Role of the anterior insula in task-level control and focal attention. Brain Struct Funct, 2010, 214 669-680. [Medline] [CrossRef]

32) Yarkoni T, Poldrack RA, Nichols TE, et al.: Large-scale automated synthesis of human functional neuroimaging data. Nat Methods, 2011, 8: 
665-670. [Medline] [CrossRef]

33) Augustine JR: Circuitry and functional aspects of the insular lobe in primates including humans. Brain Res Brain Res Rev, 1996, 22: 229-244. [Medline] [CrossRef]

34) Cole LJ, Farrell MJ, Duff EP, et al.: Pain sensitivity and fMRI pain-related brain activity in Alzheimer's disease. Brain, 2006, 129: 2957-2965. [Medline] [CrossRef]

35) Craig AD: Interoception: the sense of the physiological condition of the body. Curr Opin Neurobiol, 2003, 13: 500-505. [Medline] [CrossRef]

36) Mutschler I, Wieckhorst B, Kowalevski S, et al.: Functional organization of the human anterior insular cortex. Neurosci Lett, 2009, 457: 66-70. [Medline] [CrossRef]

37) Craig AD: How do you feel—now? The anterior insula and human awareness. Nat Rev Neurosci, 2009, 10: 59-70. [Medline] [CrossRef]

38) Ng SS: Contribution of subjective balance confidence on functional mobil- ity in subjects with chronic stroke. Disabil Rehabil, 2011, 33: 2291-2298. [Medline] [CrossRef]

39) Dieterich M, Brandt T: Vestibular system: anatomy and functional magnetic resonance imaging. Neuroimaging Clin N Am, 2001, 11: 263-273, ix ix. [Medline]

40) Lopez C, Blanke O, Mast FW: The human vestibular cortex revealed by coordinate-based activation likelihood estimation meta-analysis. Neuroscience, 2012, 212: 159-179. [Medline] [CrossRef]

41) Dieterich M, Bense S, Lutz S, et al.: Dominance for vestibular cortical function in the non-dominant hemisphere. Cereb Cortex, 2003, 13: 994 1007. [Medline] [CrossRef]

42) Bonan IV, Colle FM, Guichard JP, et al.: Reliance on visual information after stroke. Part I: Balance on dynamic posturography. Arch Phys Med Rehabil, 2004, 85: 268-273. [Medline] [CrossRef] 